\title{
Inocybe brijunica sp. nov., a New Ectomycorrhizal Fungus from Mediterranean Croatia Revealed by Morphology and Multilocus Phylogenetic Analysis
}

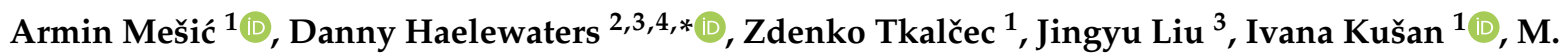 \\ Catherine Aime ${ }^{3}\left(\mathbb{D}\right.$ and Ana Pošta ${ }^{1}$ \\ 1 Laboratory for Biological Diversity, Ruđer Bošković Institute, Bijenička cesta 54, HR-10000 Zagreb, Croatia; \\ amesic@irb.hr (A.M.); ztkalcec@irb.hr (Z.T.); ikusan@irb.hr (I.K.); aposta@irb.hr (A.P.) \\ 2 Faculty of Science, University of South Bohemia, Branišovská 31, 37005 České Budějovice, Czech Republic \\ 3 Department of Botany and Plant Pathology, Purdue University, 915 W. State Street, \\ West Lafayette, IN 47907, USA; liu1643@purdue.edu (J.L.); maime@purdue.edu (M.C.A.) \\ 4 Research Group Mycology, Department of Biology, Ghent University, K.L. Ledeganckstraat 35, \\ 9000 Ghent, Belgium \\ * Correspondence: danny.haelewaters@gmail.com
}

check for

updates

Citation: Mešić, A.; Haelewaters, D.; Tkalčec, Z.; Liu, J.; Kušan, I.; Aime, M.C.; Pošta, A. Inocybe brijunica sp. nov., a New Ectomycorrhizal Fungus from Mediterranean Croatia Revealed by Morphology and Multilocus Phylogenetic Analysis. J. Fungi 2021, 7, 199. https://doi.org/10.3390/ jof7030199

Academic Editor: Anush Kosakyan

Received: 9 February 2021

Accepted: 8 March 2021

Published: 10 March 2021

Publisher's Note: MDPI stays neutral with regard to jurisdictional claims in published maps and institutional affiliations.

Copyright: (c) 2021 by the authors. Licensee MDPI, Basel, Switzerland. This article is an open access article distributed under the terms and conditions of the Creative Commons Attribution (CC BY) license (https:// creativecommons.org/licenses/by/ $4.0 /)$.

\begin{abstract}
A new ectomycorrhizal species was discovered during the first survey of fungal diversity at Brijuni National Park (Croatia), which consists of 14 islands and islets. The National Park is located in the Mediterranean Biogeographical Region, a prominent climate change hot-spot. Inocybe brijunica sp. nov., from sect. Hysterices (Agaricales, Inocybaceae), is described based on morphology and multilocus phylogenetic data. The holotype collection was found at the edge between grassland and Quercus ilex forest with a few planted Pinus pinea trees, on Veli Brijun Island, the largest island of the archipelago. It is easily recognized by a conspicuous orange to orange-red-brown membranaceous surface layer located at or just above the basal part of the stipe. Other distinctive features of I. brijunica are the medium brown, radially fibrillose to rimose pileus; pale to medium brown stipe with fugacious cortina; relatively small, amygdaliform to phaseoliform, and smooth basidiospores, measuring ca. 6.5-9 $\times 4-5.5 \mu \mathrm{m}$; thick-walled, utriform, lageniform or fusiform pleurocystidia (lamprocystidia) with crystals and mostly not yellowing in alkaline solutions; cheilocystidia of two types (lamprocystidia and leptocystidia); and the presence of abundant caulocystidia only in the upper 2-3 mm of the stipe. Phylogenetic reconstruction of a concatenated dataset of the internal transcribed spacer region (ITS), the nuclear $28 \mathrm{~S}$ rRNA gene (nrLSU), and the second largest subunit of RNA polymerase II (rpb2) resolved I. brijunica and I. glabripes as sister species.
\end{abstract}

Keywords: 1 new taxon; Agaricomycetes; Basidiomycota; biodiversity; climate change; Inocybaceae; taxonomy

\section{Introduction}

The Brijuni archipelago consists of 14 islands and islets located in the Adriatic Sea (northern Mediterranean, Europe), near the southwestern coast of the Istrian peninsula. The archipelago is home to Brijuni National Park [1], which covers $33.9 \mathrm{~km}^{2}$ of protected area, including the surrounding sea. The islands' surface area covers $7.4 \mathrm{~km}^{2}$; Veli Brijun is the largest island with $5.7 \mathrm{~km}^{2}$ and is devoid of permanent inhabitants. The National Park was established in 1983 to protect valuable marine and coastal (land) ecosystems and their biodiversity. The area is floristically rich, covered with evergreen vegetation and home to more than 400 native and exotic plant species mostly of Mediterranean origin. The Brijuni archipelago is characterized by a northern Mediterranean climate [1] with an average annual temperature of $13.9^{\circ} \mathrm{C}$, annual average precipitation of $817 \mathrm{~mm}$, and a relatively high average air humidity of $76 \%$. 
During the 20th century, the air temperature increased globally by $0.74{ }^{\circ} \mathrm{C}$, but the temperature rise in the Mediterranean area was higher-up to $1.5-4{ }^{\circ} \mathrm{C}$ depending on the region [2]. Following the Regional Climate Change Index (RCCI), the Mediterranean region is one of the most prominent climate change hot-spots in the world [3,4]. Models predicting the intensity of future climate change in this area are not optimistic. According to Mariotti et al. [5], land areas of the Mediterranean will gradually become drier; models predict $8 \%$ less precipitation in 2020-2049 compared to 1950-2000, a number that is projected to increase to $15 \%$ in 2070-2099. Drying in the northern Mediterranean [4,6] is projected to occur year-round, which will increase water stress for ecosystems if climate change continues at the current rate. Therefore, in the future, we can expect an increase of devastating climatic events (floods, storms, and droughts), more attacks of organisms that cause diseases, and a higher number of invasive species that will compete with indigenous species populations. These events could have a strong negative impact on the Mediterranean forest ecosystems [2] as well as on fruiting and existence of drought-sensitive fungal species in the area [7].

The ratio of plant species to macrofungal species is conservatively estimated as 1:6 [8]. Given the high number of plant species in the Brijuni Archipelago, an equally high diversity of fungal species is expected. Currently, however, there are no published data on fungi from this area. And even though fungal taxonomy has a long history in Europe, many species continue to be described from the continent. In 2019, $23 \%$ of newly described species of fungi were from Europe [9]. Given all this, it can be expected that undescribed species may be discovered at the Brijuni Islands. Initial field trips by Croatian mycologists aiming to document the fungal diversity of Brijuni National Park were carried out during the fall season in 2014, 2015, 2016, and 2020. In total, 546 records of basidiomycete fungi were made; 184 samples were collected and deposited in the Croatian National Fungarium $(\mathrm{CNF})$ in Zagreb, Croatia. One of the most common genera found was Inocybe (Fr.) Fr. (Agaricomycetes, Agaricales, Inocybaceae), with 28 collections.

Inocybe sensu lato (s.l.) is a highly diverse genus of ectomycorrhizal mushrooms [10] currently with about 1000 accepted species [11]. It belongs to the family Inocybaceae Jülich. The species diversity within Inocybe s.l. is best known in Europe, especially in its central countries-Austria, France, Germany, the Netherlands, and Switzerland-with more than 450 species recorded [12]. Current ongoing studies are exploring the diversity of the genus in Europe and many new species have been recently described [13-22].

According to the taxonomic treatment by Matheny et al. [23] based on a six-locus phylogeny, the family Inocybaceae now consists of seven genera: Auritella Matheny \& Bougher, Inocybe sensu stricto (s.s.), Inosperma (Kühner) Matheny \& Esteve-Rav., Mallocybe (Kuyper) Matheny, Vizzini \& Esteve-Rav., Nothocybe Matheny \& K.P.D. Latha, Pseudosperma Matheny \& Esteve-Rav., and Tubariomyces Esteve-Rav. \& Matheny. The largest genus remains Inocybe s.s. with about 850 known species worldwide. Members of Inocybe s.s. can be distinguished from other genera in the family by the presence of pleurocystidia and basidiospores (with a distinct apiculus) that range from amygdaliform to ellipsoid, subcylindrical, angular, nodulose, or spinose in shape [23].

On 16 November 2016, during our fungal diversity research on the island of Veli Brijun, basidiomata of an interesting fungus belonging to Inocybe s.s. were found. Its basidiomata were macroscopically striking by the presence of an orange to orange-redbrown membranaceous surface layer (possibly a remnant of universal veil) in the basal part of the stipe - an unusual feature in the genus. Further detailed molecular phylogenetic and morphological analyses confirmed that the species was hitherto unknown to science. Therefore, it is here described as I. brijunica sp. nov.

\section{Materials and Methods}

\subsection{Description of the Research Area}

The holotype collection of Inocybe brijunica was collected on Veli Brijun Island. The biogeographical position and a long history of human interventions have shaped the 
landscape of Veli Brijun Island, merging natural and anthropogenic elements. The island is mostly covered by a thermophilous forest with holm oak (Quercus ilex) (including those in the maquis degradation stage), planted alleys or groves of pine trees (Pinus halepensis Mill. and P. pinea L.), cypresses (Cupressus sempervirens L.), cedars (Cedrus spp.), and parks and lawns often used as golf courses.

The Inocybe collection was found on the edge of the mature thermophilous $Q$. ilex forest and a lawn grazed by large herbivores (fallow deer [Dama dama L.], axis deer [Axis axis Erxleben], and European mouflon [Ovis gmelini musimon Pall.]) and occasionally machinemowed by park staff. In addition, a few mature planted trees of $P$. pinea were present at the forest edge. Basidiomata of I. brijunica were found at ca. $70 \mathrm{~m}$ from the sea, epigeous on the soil covered with a shallow layer of oak and pine litter intermixed with scattered short grasses. The understory of the surrounding forest was devoid of herbaceous plants and shrubs due to the presence of large herbivores.

\subsection{Morphological Study}

The species description is based on a single but large collection consisting of 20 basidiomata. Macroscopic characters were documented with a Canon EOS 5D digital camera equipped with a Canon MR-14EX macro ring flash (Canon Europe, Uxbridge, UK). Microscopic features were observed by brightfield and phase contrast microscopy using a BX51 optical microscope (Olympus, Hamburg, Germany) under magnification up to 1500× and photographed with a Canon EOS M50 digital camera. Descriptions and images of microscopic characters were made from rehydrated specimens mounted in $2.5 \%$ potassium hydroxide $(\mathrm{KOH})$, except for cystidia that were observed in $3 \%$ ammonium hydroxide $\left(\mathrm{NH}_{4} \mathrm{OH}\right)$. Micromorphological terminology mostly follows Clémençon [24]. Line drawings were made by J.L. with PITT artist pens (Faber-Castell, Nürnberg, Germany) based on digital images.

Amyloid and dextrinoid reactions of basidiospores were tested in Melzer's reagent [25]. Randomly selected basidiospores from photographs of lamellae mounts were measured with Motic Images Plus 2.0 software (Motic Europe, Barcelona, Spain). The length/width ratio of basidiospores is given as the " $\mathrm{Q}$ " value (min-av.-max). Average basidiospore and pleurocystidia lengths, widths, and $Q$ values are shown in italics. Numbers in square brackets $[X / Y / Z]$ denote $X$ elements measured in $Y$ basidiomata of $Z$ collections. Measurements of cystidia do not include crystals present at the apex. Type material was preserved by drying on a flow of hot air at maximum temperature of $50^{\circ} \mathrm{C}$. The holotype is deposited at CNF, and an isotype is deposited at PUL (Kriebel Herbarium, Purdue University, West Lafayette, IN, USA).

\subsection{DNA Extraction, PCR Amplification, and Sequencing}

Genomic DNA was extracted from parts of the lamellae using the QIAamp DNA Micro Kit (Qiagen, Valencia, CA, USA). The first $~ 1100 \mathrm{bp}$ of the nuclear $18 \mathrm{~S}$ nuclear ribosomal RNA gene (nrSSU), the internal transcribed spacer region of the rDNA (ITS, consisting of ITS1-5.8S-ITS2), the first $1400 \mathrm{bp}$ of the nuclear 28S rRNA gene (nrLSU), and the second largest subunit of RNA polymerase II gene ( $r p b 2)$ were amplified [26]. The following primers were used: NS1, NS2, and NS4 [27] for nrSSU; ITS9mun [28] and ITS4 [27] for ITS; LR0R, LR5, and LR7 for nrLSU [29,30]; and RBP2-b6F, RPB2-b7R, and RPB2-b7.1R for $r p b 2$ [31]. Amplifications were done in $25 \mu \mathrm{L}$ reactions, containing $12.5 \mu \mathrm{L}$ of Promega $2 \times$ PCR Master Mix (Promega Co., Madison, WI, USA), $1.25 \mu \mathrm{L}$ of each $10 \mu \mathrm{M}$ primer, $9.0 \mu \mathrm{L}$ of $\mathrm{H}_{2} \mathrm{O}$, and $1.0 \mu \mathrm{L}$ of template DNA. PCR conditions for nrSSU, ITS, and nrLSU followed Haelewaters et al. [32]. For $r p b 2$, PCR conditions were as follows: initial denaturation at $95^{\circ} \mathrm{C}$ for $5: 00 \mathrm{~min}$; followed by 40 cycles of denaturation at $95^{\circ} \mathrm{C}$ for $30 \mathrm{~s}$, annealing at $55^{\circ} \mathrm{C}$ for $45 \mathrm{~s}$, and extension at $72{ }^{\circ} \mathrm{C}$ for $45 \mathrm{~s}$; and final extension at $72{ }^{\circ} \mathrm{C}$ for 7:00 min. All amplifications were performed using the Eppendorf Mastercycler EP Thermal Cycler (Hauppauge, NY, USA). Purification of successful PCR products and sequencing in both directions using the amplification primers were outsourced to Genewiz (South 
Plainfield, NJ, USA). Sequence reads were assembled and edited using Sequencher 5.4.6 for Windows software (Gene Codes Corporation, Ann Arbor, MI, USA). Assembled sequences were deposited at the National Center for Biotechnology Information (NCBI) GenBank database, under accession numbers MN749503-MN749504 (nrSSU), MN749370-MN749371 (ITS), MN749492-MN749493 (nrLSU), and MT878448-MT878449 (rpb2).

\subsection{Sequence Alignment and Phylogenetic Analysis}

Newly obtained ITS sequences were BLAST searched against NCBI GenBank's standard $n r / n t$ nucleotide database (https:/ /blast.ncbi.nlm.nih.gov/Blast.cgi, accessed on 9 August 2020), resulting in three isolates of Inocybe glabripes Ricken (sect. Hysterices Stangl \& J. Veselský) as top results, which shared between $91.49 \%$ and $91.90 \%$ identity (GenBank accession numbers KX602255, MH216096, MN947389). Following this result, ITS, nrLSU, and $r p b 2$ sequences of Inocybe sect. Hysterices species [26,31,33-35] were downloaded for phylogenetic analysis.

Sequences were aligned by locus using MUSCLE version 3.7 [36], available through the Cipres Science Gateway [37]. Next, sequences in the ITS dataset were trimmed at the conserved motifs 5'-CATTA- $3^{\prime}$ ( $3^{\prime}$ end of the nrSSU) and 5'-GACCT(CAAA ... ) $-3^{\prime}$ ( $5^{\prime}$ end of the nrLSU) [38]. Because the different portions of the ITS spacer region (the two spacers and 5.8S) have different rates of evolution [39,40], the ITS1 and ITS2 spacers and the $5.8 \mathrm{~S}$ conserved gene were extracted and treated as individual partitions in the multilocus analysis. Sequences in the nrLSU dataset were also trimmed to start with the conserved motif $5^{\prime}-\mathrm{GACCT}(\mathrm{CAAA} \ldots .)-.3^{\prime}$. Ambiguously aligned regions were removed using trimAl version 1.3 [41], with $-\mathrm{gt}=0.6$ and - cons $=0.5$.

Evolutionary models for nucleotide substitution were selected for each partition (ITS1, 5.8S, ITS2, nrLSU, rpb2) using ModelFinder Plus [42], considering the Akaike Information Criterion. The data for each locus were combined in MEGA7 [43] to create a supermatrix of 2752 characters for 28 isolates representing ten species in Inocybe sect. Hysterices and two species in Inocybe sect. Lactiferae serving as outgroup taxa (details in Table 1). Maximum likelihood (ML) was inferred under partitioned models using IQ-TREE 1.6.7 [44,45]. Ultrafast bootstrapping was done with 1000 replicates [46].

Table 1. Overview of Inocybe isolates used in phylogenetic analyses. Newly generated sequences are in boldface. ${ }^{\mathrm{T}}$ stands for type specimens.

\begin{tabular}{|c|c|c|c|c|c|c|}
\hline Species & Section & Isolate & Locality & ITS & nrLSU & $r p b 2$ \\
\hline Inocybe aeruginascens & Hysterices & JG270502 & Germany & GU949590 & JN974970 & \\
\hline Inocybe aeruginascens & Hysterices & JG310508 & Germany & GU949591 & MH220256 & MH249787 \\
\hline Inocybe aeruginascens & Hysterices & PC111007 & South Africa & GU949592 & MH220257 & \\
\hline Inocybe chondroderma & Hysterices & PBM1760 & British Columbia & GU949586 & MH220258 & \\
\hline Inocybe chondroderma & Hysterices & PBM1776 & Washington & GU949579 & JN974967 & MH249789 \\
\hline Inocybe brijunica ${ }^{\mathrm{T}}$ & Hysterices & D. Haelew. F-1610a & Croatia & MN749370 & MN749492 & MT878448 \\
\hline Inocybe brijunica $^{\mathrm{T}}$ & Hysterices & D. Haelew. F-1610b & Croatia & MN749371 & MN749493 & MT878449 \\
\hline Inocybe dulciolens ${ }^{\mathrm{T}}$ & Lactiferae & PBM2646 & Tennessee & MH216088 & MH220265 & MH249796 \\
\hline Inocybe dulciolens & Lactiferae & PBM2450 & New York & MH216087 & MH220264 & MH249795 \\
\hline Inocybe dulciolens & Lactiferae & LVK13340 & New Jersey & MH216084 & MH220261 & MH249792 \\
\hline Inocybe erinaceomorpha & Lactiferae & EL128/05 & Sweden & AM882735 & AM882735 & \\
\hline Inocybe erinaceomorpha & Lactiferae & JV14756F & Sweden & MH216089 & MH220266 & MH249797 \\
\hline Inocybe glabripes & Hysterices & JV7318F & Finland & MH216096 & & MH249803 \\
\hline Inocybe hystrix & Hysterices & HRL11842 & Quebec & KX897428 & & \\
\hline Inocybe hystrix & Hysterices & PBM3300 & North Carolina & GU949588 & MH220275 & \\
\hline Inocybe hystrix & Hysterices & RS31493 & Finland & & AY380380 & AY337381 \\
\hline Inocybe hystrix & Hysterices & SJ020824 & Sweden & AM882810 & AM882810 & \\
\hline Inocybe aff. hystrix & Hysterices & REH7405 & Costa Rica & GU949589 & JN974969 & MH249806 \\
\hline
\end{tabular}


Table 1. Cont

\begin{tabular}{|c|c|c|c|c|c|c|}
\hline Species & Section & Isolate & Locality & ITS & nrLSU & $r p b 2$ \\
\hline Inocybe melanopus $^{\mathrm{T}}$ & Hysterices & Stz3641 & Washington & & HQ201359 & \\
\hline Inocybe melanopus & Hysterices & BJ920904 & Sweden & AM882725 & AM882725 & \\
\hline Inocybe melanopus & Hysterices & JV4986 & Finland & AM882727 & AM882727 & \\
\hline Inocybe melanopus & Hysterices & PBM3975 & Tennessee & & MH220276 & MH249807 \\
\hline Inocybe melanopus & Hysterices & TAA185135 & Estonia & AM882726 & & \\
\hline Inocybe aff. pallidobrunnea & Hysterices & PBM1957 & Washington & MH216098 & MH220277 & MH249808 \\
\hline Inocybe aff. pallidobrunnea & Hysterices & PBM2242 & Washington & MH216099 & JN974968 & MH249809 \\
\hline Inocybe sp. & Hysterices & PBM578 & Washington & MH216104 & JN974961 & MH249813 \\
\hline Inocybe sp. & Hysterices & TR170-02 & New Guinea & & JN974964 & MH249814 \\
\hline Inocybe sp. & Hysterices & TR180-02 & New Guinea & & JN974965 & \\
\hline
\end{tabular}

\section{Results}

\subsection{Phylogenetic Inference}

The final multilocus dataset (Supplementary File S1) consists of 2752 characters, of which 425 are parsimony-informative and 2197 are constant. The number of total and parsimony-informative characters by locus as well as their selected evolutionary models as selected by ModelFinder Plus are presented in Table 2. The best-scoring ML tree $(-\ln L=8722.045120)$ is shown in Figure 1. The topology is mostly congruent with Matheny and Kudzma [26], although support has improved for certain nodes. Inocybe brijunica sp. nov. is retrieved as a sister species of I. glabripes with maximum support. This set (I. brijunica, I. glabripes) is highly supported as sister to the clade holding I. chondroderma D.E. Stuntz ex Matheny, Norvell \& E.C. Giles and I. aff. pallidobrunnea Kauffman.

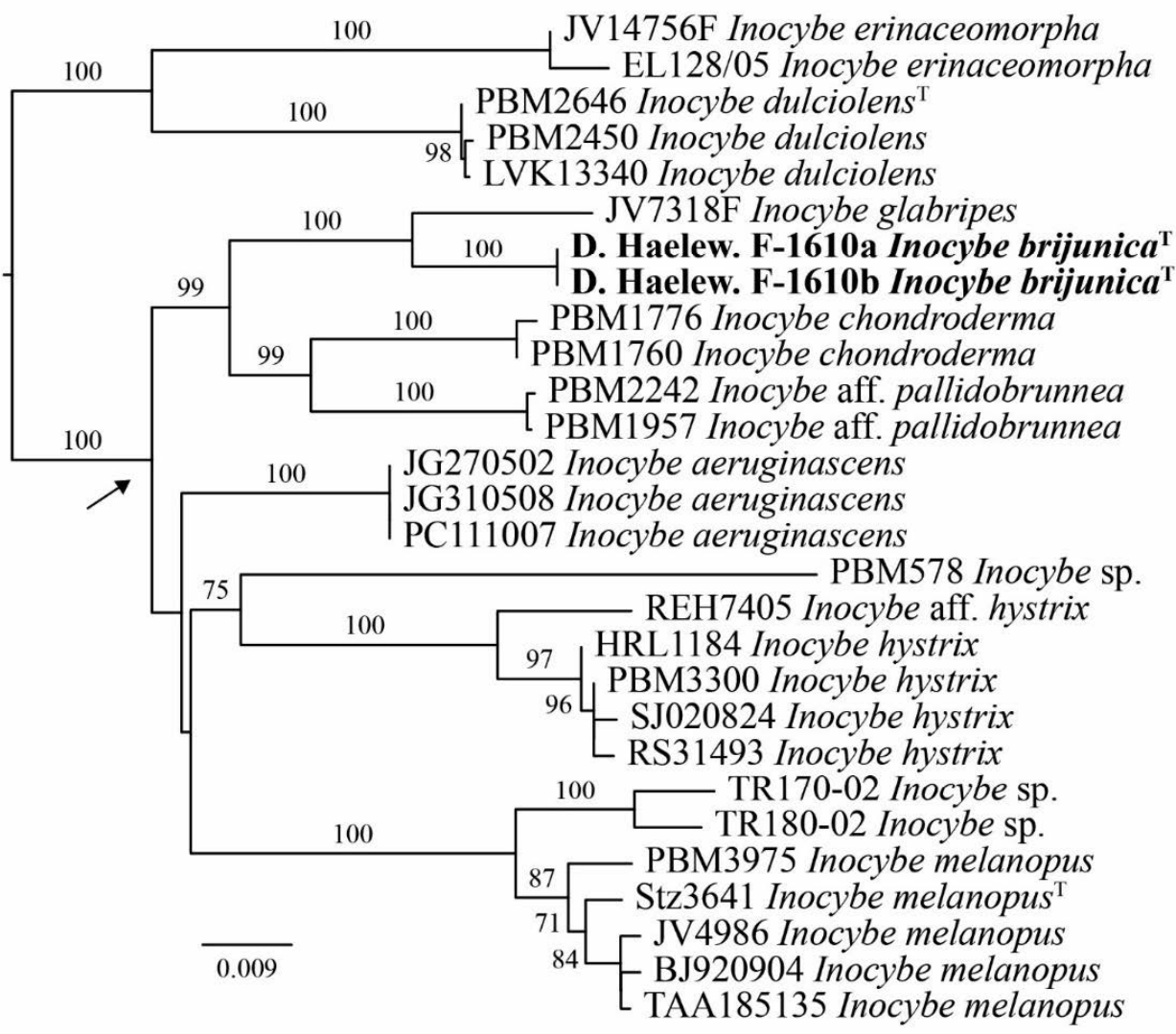

Figure 1. The best-scoring ML tree $(-\operatorname{lnL}=8722.045120)$ of Inocybe sect. Hysterices (represented by the arrow) reconstructed from a concatenated ITS-nrLSU-rpb2 dataset of 28 isolates. The tree topology is the result of ML inference performed in IQ-TREE. For each node, the ML bootstrap $(\geq 70)$ is presented above or in front of the branch leading to that node. The new species is in boldface. ${ }^{\mathrm{T}}$ stands for type specimens. 
Table 2. Overview of number of characters (total, informative, constant) and selected model of nucleotide substitution, by locus.

\begin{tabular}{ccccccc}
\hline Locus & Sequences & Sites & Informative & Constant & Model & - $\operatorname{lnL}$ \\
\hline ITS1 & 23 & 246 & 92 & 134 & HKY + F + G4 & 1306.690 \\
$5.8 S$ & 23 & 158 & 4 & 153 & TIM3e & 249.420 \\
ITS2 & 23 & 203 & 79 & 113 & TPM3u + F + G4 & 1034.365 \\
nrLSU & 25 & 1379 & 94 & 1257 & TN + F+I & 3068.786 \\
$r p b 2$ & 16 & 766 & 156 & 540 & TN + F+I & 2935.101 \\
\hline
\end{tabular}

\subsection{Taxonomy}

Inocybe brijunica Mešić, Tkalčec \& Haelew., sp. nov.

Figures $2-4$.

Mycobank MB838152

Typification: CROATIA. ISTRIA COUNTY: Brijuni National Park, Veli Brijun Island, $44^{\circ} 55^{\prime} 04^{\prime \prime} \mathrm{N} 13^{\circ} 46^{\prime} 33^{\prime \prime} \mathrm{E}$, on the edge of grassland and forest of Quercus ilex L. with a few planted Pinus pinea L. trees along the forest edge, 16 November 2016, A. Mešić \& Z. Tkalčec (holotype, CNF 1/7345; isotype, PUL F27673). GenBank (ex-isotype DNA isolate D. Haelew. F-1610a): $\mathrm{nrSSU}=$ MN749503, ITS = MN749370, $\mathrm{nrLSU}=\mathrm{MN749492,} r p b 2=$ MT878448; (ex-isotype DNA isolate D. Haelew. F-1610b) nrSSU $=$ MN749504, ITS $=$ MN749371, nrLSU $=$ MN749493, $r p b 2=$ MT878449.

Etymology: Referring to the Brijuni archipelago, where the holotype was collected.

Description: Pileus 15-22 mm wide, obtusely (sub)conical with inflexed margin when young; convex to plano-convex, subumbonate and with deflexed margin at maturity; margin entire, occasionally with short radial splits; surface dry, finely radially fibrillose at first, then intensely fibrillose, rimulose to rimose, finally often partially cracked in small, shallow patches showing the paler flesh underneath; mostly medium brown, often with orange (fulvous brown) or reddish tones, less often light or dark brown where more deeply cracked; younger basidiomata often with rather inconspicuous, fibrillous, whitish veil remnants in marginal zone. Lamellae adnexed, subcrowded, $\mathrm{L}=$ ca. 40-50, $1=1-3$, (sub)ventricose; whitish at first, then pale yellowish brown, finally light brown; edges fimbriate to slightly eroded, \pm concolorous with sides. Stipe $17-30 \times 2.5-4.5 \mathrm{~mm}$, subcylindrical with slightly to moderately broadened base (up to $7 \mathrm{~mm}$, sometimes submarginate); solid, surface dry, white flocculose at apex, becoming whitish longitudinally fibrillose toward base, fibrils more scattered with age, beneath the fibrils pale to medium brown; with more or less developed orange to dull orange-red or orange-red-brown, adhering, membranaceous surface layer (possibly a remnant of universal veil), at or just above the basal part of the stipe; basal tomentum scanty, whitish. Cortina (partial veil) present in young basidiomata, fibrillous, white, fugacious. Context cream, light brown when moist, not changing color on bruising, not darkening on drying. Odor spermatic. Taste not recorded. 

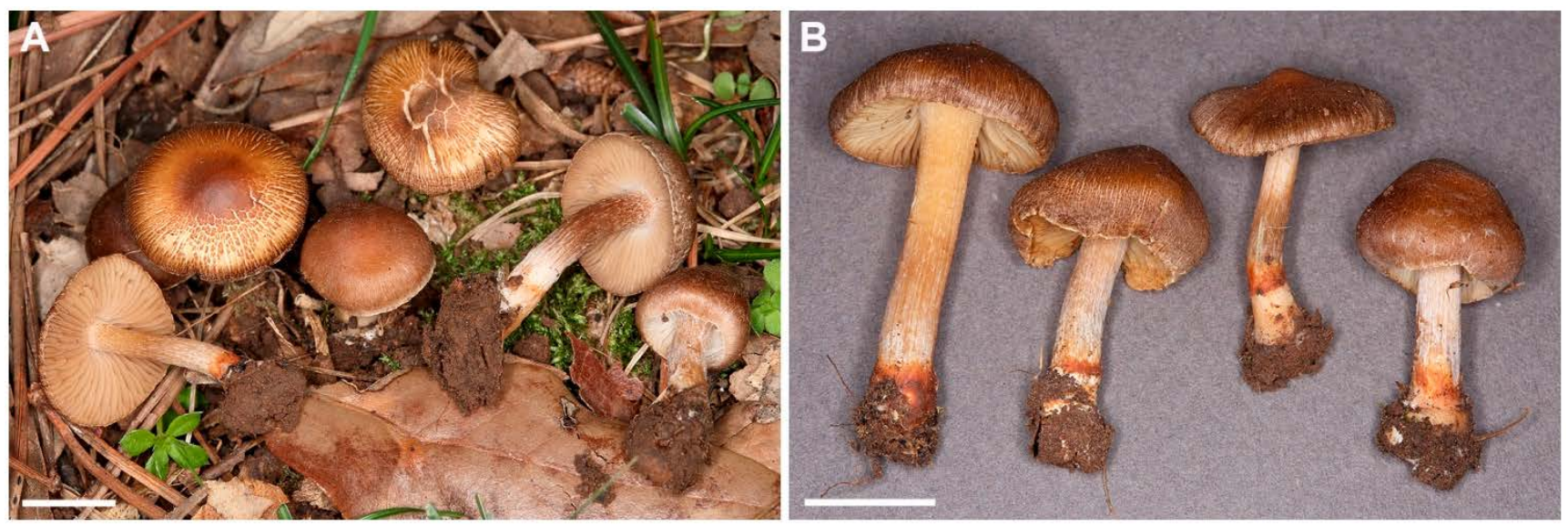

Figure 2. Inocybe brijunica (CNF 1/7345, holotype). (A) Basidiomata in situ. (B) Basidiomata in lab. Bars: A, B = 10 mm.

Basidiospores [300/3/1] (6.2-)6.6-7.5-8.8(-9.8) × (4-)4.3-4.7-5.3(-5.7) $\mu \mathrm{m}$, averages of different basidiomata 7.3-7.6 $\times 4.6-4.7 \mu \mathrm{m}, \mathrm{Q}=1.35-1.6-1.96$, av. $\mathrm{Q}=1.58-1.62$, a few very large spores occasionally present (up to ca. $12 \times 7 \mu \mathrm{m}$ ); in frontal view ellipsoid, oblong or ovoid with rounded to subacute base and rounded to acute apex, in side view amygdaliform to phaseoliform, rarely subellipsoid, with rounded base and rounded to acute apex, sometimes subangulate in both views (especially in upper part); smooth, often with small, rather indistinct, apical germ-pore, moderately thick-walled (up to $0.8 \mu \mathrm{m}$ ), pale yellow-brown in $\mathrm{KOH}$, pale brown in $\mathrm{H}_{2} \mathrm{O}$, non-amyloid and non-dextrinoid. Basidia 20-30 × 6.5-9 $\mu \mathrm{m}$, clavate, predominantly 4-spored, occasionally 2-spored, thin-walled, hyaline to yellowish. Pleurocystidia of lamprocystidia-type, very abundant, [90/4/1] 34-50-65(-70) × 9-14-21 $\mu \mathrm{m}, \mathrm{Q}=2.39-3.65-5.45$, predominantly utriform, lageniform, or fusiform, with obtuse apex of 6-9(-11) $\mu \mathrm{m}$ wide, sometimes (sub)clavate, conical with obtuse apex, narrowly ellipsoid or subcylindrical, in alkaline solutions mostly (sub)hyaline, less often with slightly yellowish wall, sometimes with dirty yellow cytoplasmic pigment, with strongly to poorly developed crystals at apex (soluble in $\mathrm{KOH}$, rarely lacking), thickwalled, wall most often gradually thickened towards the apex (up to 1-5.5 $\mu \mathrm{m}$ ). Lamellar edge heterogeneous. Cheilocystidia of two types: (a) lamprocystidia similar to pleurocystidia (although more often without crystals), scattered to abundant, and (b) leptocystidia (paracystidia) 9-30 × 5-14 $\mu \mathrm{m}$, mostly clavate, less often (sub)fusiform or utriform, hyaline to subhyaline, thin to moderately thick-walled (up to ca. $0.6 \mu \mathrm{m}$ ), scattered to abundant. Pileipellis a cutis, composed of repent, thin-walled, smooth to minutely encrusted, hyaline to pale yellow-brown hyphae, 1-5(-7) $\mu \mathrm{m}$ wide. Cells of the upper part of pileal context with brown, intracellular and partially also encrusted extracellular pigment (brown pigmented layer ca. 80-150 $\mu \mathrm{m}$ wide). Stipitipellis a cutis, composed of repent, thin-walled, smooth, ca. 2-10 $\mu \mathrm{m}$ wide hyphae. Caulocystidia mostly abundant (often crowded) in upper $2-3 \mathrm{~mm}$ of stipe length, sparsely present toward middle of the stipe; many in the form of lamprocystidia, quite similar to pleurocystidia, others very variable, narrowly utriform, lagenifom, (sub)cylindrical, clavate, urticoid or rather irregular, sometimes with subcapitate apex, some septate, hyaline, thin- to moderately thick-walled (up to ca. $1 \mu \mathrm{m}$ ); $12-100(-150) \times 4-20 \mu \mathrm{m}$. Clamp connections present, conspicuous, rather abundant in all tissues.

Distribution and ecology: Thus far only known from the holotype collection. Ectomycorrhizal, found in the Mediterranean region of Croatia (Europe), on the island of Veli Brijun in Brijuni National Park, on the edge of Quercus ilex forest, with a few planted Pinus pinea trees, edging a neighboring grassland. An ITS sequence with accession number MH310748 [47], identified as Inocybe sp., from Italy shares 99\% identity with I. brijunica (identities $=684 / 688 \mathrm{bp}$, gaps $=4 / 688$ ) and may indicate a broader distribution in the Mediterranean basin. 


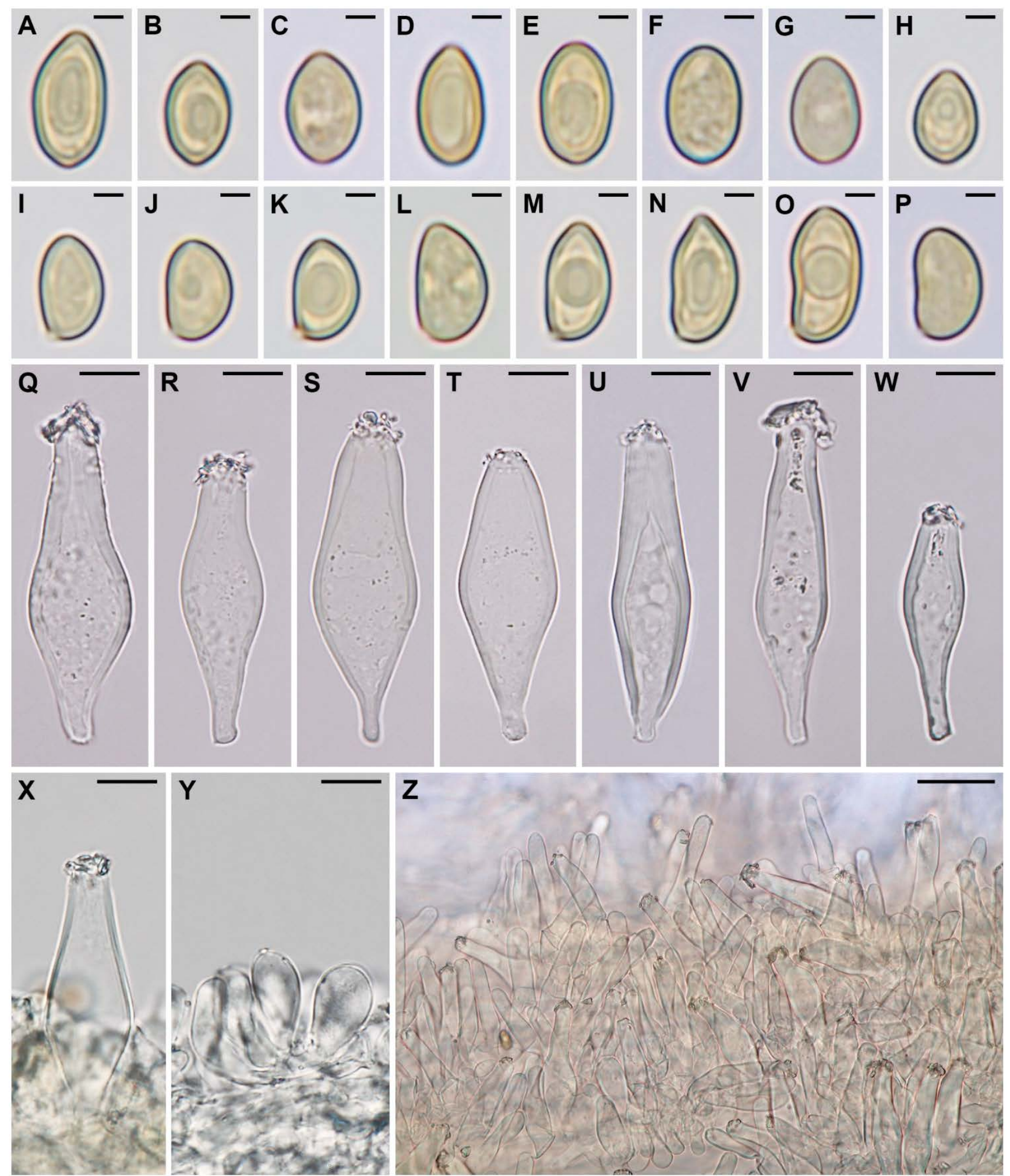

Figure 3. Inocybe brijunica (CNF 1/7345, holotype). (A-H) Basidiospores in frontal view. (I-P) Basidiospores in side view. (Q-W) Pleurocystidia. (X) Cheilolamprocystidium. (Y) Cheiloleptocystidia. (Z) Caulocystidia. Bars: $(\mathbf{A}-\mathbf{P})=2 \mu \mathrm{m}$, $(\mathbf{Q}-\mathbf{Y})=10 \mu \mathrm{m}, \mathbf{Z}=30 \mu \mathrm{m}$. 

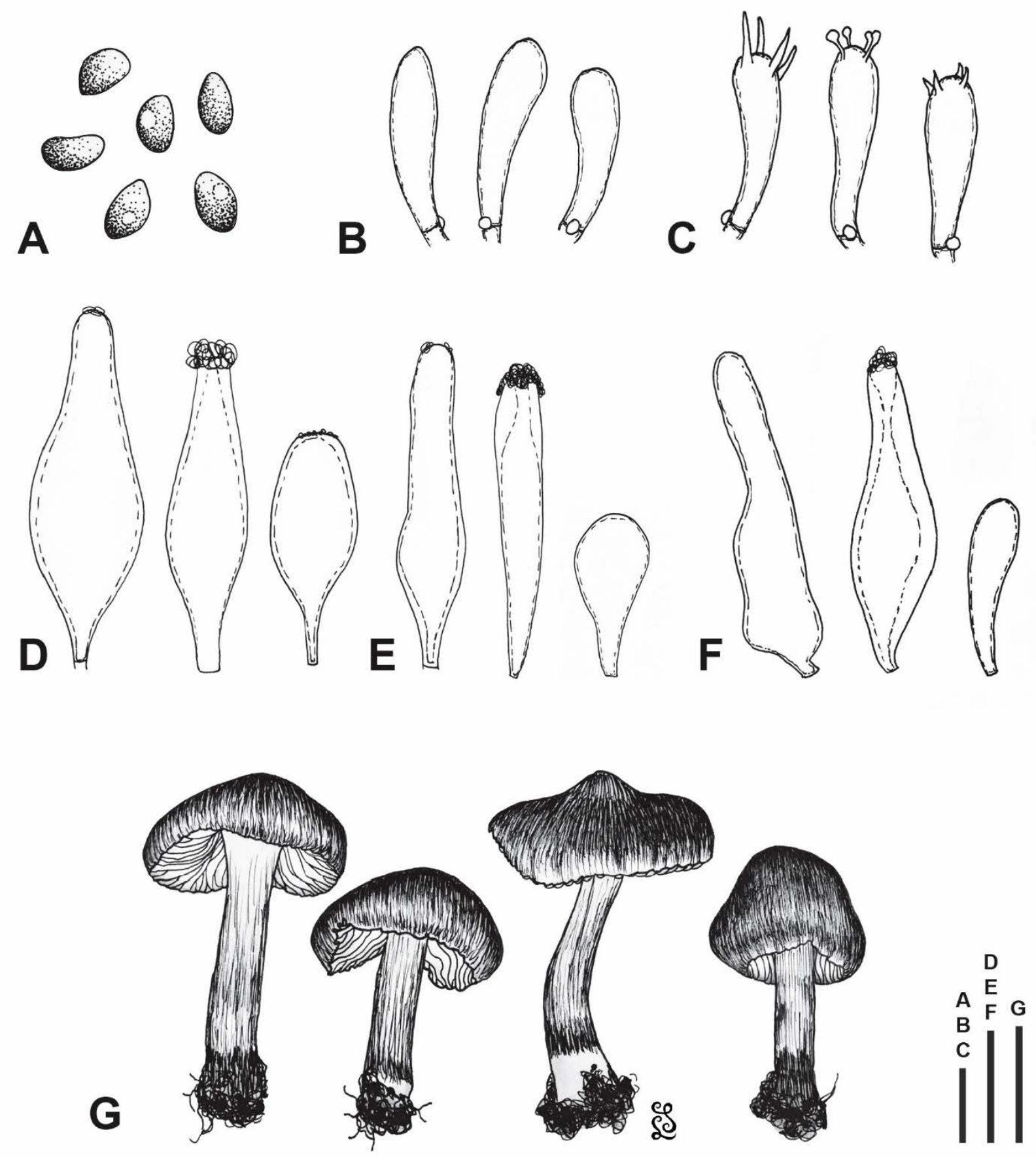

Figure 4. Inocybe brijunica (CNF 1/7345, holotype). (A) Basidiospores. (B) Basidioles. (C) Basidia. (D) Pleurocystidia. (E) Cheilocystidia). (F) Caulocystidia. (G) Basidiomata. Bars: $(\mathbf{A}-\mathbf{C})=10 \mu \mathrm{m} ;(\mathbf{D}-\mathbf{F})=20 \mu \mathrm{m} ;(\mathbf{G})=10 \mathrm{~mm}$.

\section{Discussion}

The results of our multilocus phylogenetic analysis and morphological study place I. brijunica in sect. Hysterices [48]. Basidiomata produced by species belonging to this section (in the original sense) possess a squamulose pileus and stipe, lack violaceous tones, and have amygdaliform basidiospores. Matheny and Kudzma [26] emended the section to include taxa with non-squarrose basidiomata. Macromorphologically, I. brijunica can be easily recognized from all other Inocybe species by a conspicuous orange to orangered-brown membranaceous surface layer present at or just above the basal part of the stipe. Other important morphological characters are: medium brown pileus with radially fibrillose to rimose surface; pale to medium brown stipe with slightly to moderately 
broadened (or sometimes submarginate) base; presence of fugacious cortina in young basidiomata; spermatic odor; color of context unchanged upon bruising; relatively small, amygdaliform to phaseoliform (and sometimes subangulate), smooth basidiospores (ca. 6.5-9 $\times 4-5.5 \mu \mathrm{m}$ ); pleurocystidia as utriform, lageniform, or fusiform, thick-walled (up to 1-5.5 $\mu \mathrm{m}$ ) lamprocystidia, mostly with crystals and not yellowing in alkaline solutions; cheilocystidia of two types (lamprocystidia and leptocystidia); and presence of abundant caulocystidia only in the upper $2-3 \mathrm{~mm}$ of stipe length.

The basidiospores of the morphologically and phylogenetically closest species, I. glabripes, are very similar in size, measuring ca. $6-8 \times 4-5 \mu \mathrm{m}[49,50]$, but they are readily distinguished by being amygdaliform but not phaseoliform as in I. brijunica. In addition, the cystidial walls of I. glabripes are thinner (up to $2(-2.5) \mu \mathrm{m}$ thick). Inocybe glabripes is a widespread species occurring in parks and open woodlands on predominantly alkaline soils from the Mediterranean region to the boreal zone of Europe [51], which forms ectomycorrhizae exclusively with broadleaved trees. So far, the species has been found in symbiotic relationship with trees in the genera Betula L., Fagus L., Populus L., Quercus L., Tilia L. [49-51], and with Castanea sativa Mill. [52]. It can be expected that its sister species I. brijunica also forms ectomycorrhizal relationships only with broadleaved trees, such as Quercus ilex at the holotype locality.

Inocybe pseudobrunnea Alessio, which grows under Abies alba Mill. (Pinales, Pinaceae), has a similar phaseoliform, but somewhat larger basidiospores, 8.5-10.5(11) $\times 4.5-6 \mu \mathrm{m}$, and its cystidia are rather bright yellow in ammonia solution [53], a characteristic that rarely occurs in I. brijunica. Inocybe gracilenta E. Ludw., only known from the type collection in Sweden, a damp locality under Alnus sp. (Fagales, Betulaceae), Populus tremula L. and Salix sp. (Malpighiales, Salicaceae), has amygdaliform but not phaseoliform basidiospores, which are otherwise similar in size compared to I. brijunica, 7-8.5(9.5) $\times$ 4.5-5.5 $\mu \mathrm{m}$ [51]. Additional differences are the papillate pileus and the slenderer (up to $2 \mathrm{~mm}$ wide) and white to faintly creamcolored stipe [51]. The Mediterranean species I. barrasae Esteve-Rav., described from Spain and fruiting in spring (April-May) in thermophilous Mediterranean Quercus-Cistus forests, has amygdaliform-shaped basidiospores that are larger and more elongated (8-11.5 $\times 4.5-5.5 \mu \mathrm{m}$, av. $\mathrm{Q}=1.85$ ), and bright yellow-colored cystidia in ammonia solution [54]. Inocybe aerea E. Ludw., another species only known from the holotype collection in Germany [51], has amygdaliform to ovoid and slightly larger basidiospores $(7.5-10.5 \times 5-6 \mu \mathrm{m})$, an ochraceous yellow and more slender (up to $2 \mathrm{~mm}$ wide) stipe, and thinner-walled cystidia (walls 0.2-2 $(-3) \mu \mathrm{m}$ thick). The North American species I. pyrotricha Stuntz [55] has orange to cinnamon or rusty-red fibrils on the stipe, like I. brijunica, but differs by slightly larger $(7.5-10 \times 4.5-6 \mu \mathrm{m})$ basidiospores, longer pleurocystidia $(66-80 \times 13.5-16.5 \mu \mathrm{m})$, and violaceous tinges in young lamellae and upper parts of the stipe.

Supplementary Materials: The following supplementary material is available online at https:// www.mdpi.com/2309-608X/7/3/199/s1, File S1: Aligned, concatenated dataset of Inocybe sect. Hysterices, consisting of five partitions (ITS1, 5.8S, ITS2, nrLSU, rpb2).

Author Contributions: Conceptualization, A.M., D.H., and Z.T.; methodology, A.M., D.H., Z.T., and J.L.; phylogenetic analysis, D.H.; data curation, D.H., I.K., and A.P.; writing-original draft preparation, A.M., D.H., and Z.T.; writing-review and editing, A.M., D.H., Z.T., I.K., M.C.A., A.P.; visualization, D.H., Z.T., and J.L.; supervision, D.H. and A.P.; project administration, D.H.; funding acquisition, A.M., D.H., and M.C.A. All authors have read and agreed to the published version of the manuscript.

Funding: This work was supported in part by the Croatian Science Foundation (HRZZ-IP-201801-1736 to A.M., Z.T., I.K., A.P.; HRZZ-2018-09-7081 to A.P.), the National Science Foundation (DEB-2018098 to D.H.), and the USDA National Institute of Food and Agriculture (Hatch project 1010662 to M.C.A). 
Acknowledgments: A.M. and Z.T. are grateful to Sandro Dujmović, former director of Brijuni National Park, for research support and to Martina Hervat for the help with the literature. P. Brandon Matheny (University of Tennessee-Knoxville, USA) is thanked for his generous help with North American Inocybe species.

Conflicts of Interest: The authors declare no conflict of interest. The funders had no role in the design of the study; in the collection, analyses, or interpretation of data; in the writing of the manuscript, or in the decision to publish the results.

\section{References}

1. Brijuni National Park Official Website. Available online: https://www.np-brijuni.hr/en/brijuni (accessed on 14 January 2021).

2. Blondel, J.; Aronson, J.; Bodiou, J.-Y.; Boeuf, G. The Mediterranean Region-Biological Diversity in Space and Time, 2nd ed.; Oxford University Press: New York, NY, USA, 2010.

3. Giorgi, F. Climate change hot-spots. Geophys. Res. Lett. 2006, 33, 1-4. [CrossRef]

4. Tuel, A.; Eltahir, E.A.B. Why is the Mediterranean a climate change hot spot? J. Clim. 2020, 33, 5829-5843. [CrossRef]

5. Mariotti, A.; Zeng, N.; Yoon, J.-H.; Artale, V.; Navarra, A.; Alpert, P.; Li, L.Z.X. Mediterranean water cycle changes: Transition to drier 21st century conditions in observations and CMIP3 simulations. Environ. Res. Lett. 2008, 3, 044001. [CrossRef]

6. Brogli, R.; Sørland, S.L.; Kröner, N.; Schär, C. Causes of future Mediterranean precipitation decline depend on the season. Environ. Res. Lett. 2019, 14, 114017. [CrossRef]

7. Antonelli, A.; Fry, C.; Smith, R.J.; Simmonds, M.S.J.; Kersey, P.J.; Pritchard, H.W.; Abbo, M.S.; Acedo, C.; Adams, J.; Ainsworth, A.M.; et al. State of the World's Plants and Fungi 2020; Royal Botanic Gardens: Kew, UK, 2020. [CrossRef]

8. Hawksworth, D.L. The fungal dimension of biodiversity: Magnitude, significance, and conservation. Mycol. Res. 1991, 95, 641-655. [CrossRef]

9. Cheek, M.; Nic Lughadha, E.; Kirk, P.; Lindon, H.; Carretero, J.; Looney, B.; Douglas, B.; Haelewaters, D.; Gaya, E.; Llewellyn, T.; et al. New scientific discoveries: Plants and fungi. Plants People Planet 2020, 2, 371-388. [CrossRef]

10. Saba, M.; Haelewaters, D.; Pfister, D.H.; Khalid, A.N. New species of Pseudosperma (Agaricales, Inocybaceae) from Pakistan revealed by morphology and multi-locus phylogenetic reconstruction. MycoKeys 2020, 69, 1-31. [CrossRef] [PubMed]

11. He, M.Q.; Zhao, R.L.; Hyde, K.D.; Begerow, D.; Kemler, M.; Yurkov, A.; McKenzie, E.H.C.; Raspé, O.; Kakishima, M.; SánchezRamírez, S.; et al. Notes, outline and divergence times of Basidiomycota. Fungal Divers. 2019, 99, 105-367. [CrossRef]

12. Bandini, D.; Oertel, B.; Ploch, S.; Ali, T.; Vauras, J.; Schneider, A.; Scholler, M.; Eberhardt, U.; Thines, M. Revision of some central European species of Inocybe (Fr.: Fr.) Fr. subgenus Inocybe, with the description of five new species. Mycol. Prog. 2018, 18, 247-294. [CrossRef]

13. Bandini, D.; Oertel, B.; Moreau, P.-A.; Thines, M.; Ploch, S. Three new hygrophilous species of Inocybe, subgenus Inocybe. Mycol. Prog. 2019, 18, 1101-1119. [CrossRef]

14. Bandini, D.; Oertel, B.; Ploch, S.; Thines, M. Inocybe heidelbergensis, eine neue Risspilz-Art der Untergattung Inocybe. Z. Mykol. 2019, 85, 195-213.

15. Bandini, D.; Oertel, B.; Schüssler, C.; Eberhardt, U. Noch mehr Risspilze: Fünzehn neue und zwei wenig bekannte Arten der Gattung Inocybe. Mycol. Bavarica 2020, 20,13-101.

16. Bandini, D.; Sesli, E.; Oertel, B.; Krisai-Greilhuber, I. Inocybe antoniniana, a new species of Inocybe section Marginatae with nodulose spores. Sydowia 2020, 72, 95-106. [CrossRef]

17. Bandini, D.; Vauras, J.; Weholt, Ø.; Oertel, B.; Eberhardt, U. Inocybe woglindeana, a new species of the genus Inocybe, thriving in exposed habitats with calcareous sandy soil. Karstenia 2020, 58, 41-59. [CrossRef]

18. Cripps, C.L.; Larsson, E.; Vauras, J. Nodulose-spored Inocybe from the Rocky Mountain alpine zone molecularly linked to European and type specimens. Mycologia 2019, 112, 133-153. [CrossRef]

19. Crous, P.W.; Carnegie, A.J.; Wingfield, M.J.; Sharma, R.; Mughini, G.; Noordeloos, M.E.; Santini, A.; Shouche, Y.S.; Bezerra, J.D.P.; Dima, B.; et al. Fungal Planet description sheets: 868-950. Persoonia 2019, 42, 291-473. [CrossRef]

20. Crous, P.W.; Cowan, D.A.; Maggs-Kölling, G.; Yilmaz, N.; Larsson, E.; Angelini, C.; Brandrud, T.E.; Dearnaley, J.D.W.; Dima, B.; Dovana, F.; et al. Fungal Planet description sheets: 1112-1181. Persoonia 2020, 45, 251-409. [CrossRef]

21. Krieglsteiner, L.G. Inocybe calosporoides-Ein neuer Risspilz aus Portugal. Südwestdeutsche Pilzrundsch. 2019, 55, 68-72.

22. Krieglsteiner, L.G. Nomenclatural novelties. Index Fungorum 2019, 411, 1.

23. Matheny, P.B.; Hobbs, A.M.; Esteve-Raventós, F. Genera of Inocybaceae: New skin for the old ceremony. Mycologia 2019, 112, 83-120. [CrossRef] [PubMed]

24. Clémençon, H. Cytology and Plectology of the Hymenomycetes, 2nd ed.; Cramer: Stuttgart, Germany, 2012.

25. Erb, B.; Matheis, W. Pilzmikroskopie; Kosmos: Stuttgart, Germany, 1982.

26. Matheny, P.B.; Kudzma, L.V. New species of Inocybe (Inocybaceae) from eastern North America. J. Torrey Bot. Soc. 2019, 146, 213-235. [CrossRef]

27. White, T.J.; Bruns, T.; Lee, S.; Taylor, J. Amplification and direct sequencing of fungal ribosomal RNA genes for phylogenetics. In PCR Protocols: A Guide to Methods and Applications; Innis, M.A., Gelfand, D.H., Sninsky, J.J., White, T.J., Eds.; Academic Press: New York, NY, USA, 1990; pp. 315-322. [CrossRef]

28. Egger, K.N. Molecular analysis of ectomycorrhizal fungal communities. Can. J. Bot. 1995, 73, S1415-S1422. [CrossRef] 
29. Vilgalys, R.; Hester, M. Rapid genetic identification and mapping of enzymatically amplified ribosomal DNA from several Cryptococcus species. J. Bacteriol. 1990, 172, 4238-4246. [CrossRef]

30. Hopple, J.S. Phylogenetic Investigations in the Genus Coprinus Based on Morphological and Molecular Characters. Ph.D. Thesis, Duke University, Durham, NC, USA, 1994.

31. Matheny, P.B. Improving phylogenetic inference of mushrooms with RPB1 and RPB2 nucleotide sequences (Inocybe, Agaricales). Mol. Phylogenet. Evol. 2005, 35, 1-20. [CrossRef]

32. Haelewaters, D.; Toome-Heller, M.; Albu, S.; Aime, M.C. Red yeasts from leaf surfaces and other habitats: Three new species and a new combination of Symmetrospora (Pucciniomycotina, Cystobasidiomycetes). Fungal Syst. Evol. 2020, 5, 187-196. [CrossRef] [PubMed]

33. Matheny, P.B.; Norvell, L.L.; Giles, E.C. A common new species of Inocybe in the Pacific Northwest with a diagnostic PDAB reaction. Mycologia 2013, 105, 436-446. [CrossRef] [PubMed]

34. Ryberg, M.; Matheny, P.B. Asynchronous origins of ectomycorrhizal clades of Agaricales. Proc. R. Soc. B Biol. Sci. 2012, 279, 2003-2011. [CrossRef] [PubMed]

35. Ryberg, M.; Nilsson, R.H.; Kristiansson, E.; Töpel, M.; Jacobsson, S.; Larsson, E. Mining metadata from unidentified ITS sequences in GenBank: A case study in Inocybe (Basidiomycota). BMC Evol. Biol. 2008, 8, 50. [CrossRef] [PubMed]

36. Edgar, R.C. MUSCLE: Multiple sequence alignment with high accuracy and high throughput. Nucleic Acids Res. 2004, 32, 1792-1797. [CrossRef]

37. Miller, M.A.; Pfeiffer, W.; Schwartz, T. Creating the CIPRES Science Gateway for inference of large phylogenetic trees. In Proceedings of the Gateway Computing Environments Workshop (GCE), New Orleans, Louisiana, 14 November 2010; Institute of Electrical and Electronics Engineers: Piscataway, NJ, USA, 2010; pp. 1-8. [CrossRef]

38. Dentinger, B.T.; Didukh, M.Y.; Moncalvo, J.M. Comparing COI and ITS as DNA barcode markers for mushrooms and allies (Agaricomycotina). PLoS ONE 2011, 6, e25081. [CrossRef]

39. Hillis, D.M.; Dixon, M.T. Ribosomal DNA: Molecular evolution and phylogenetic inference. Q. Rev. Biol. 1991, 66, 411-453. [CrossRef]

40. Haelewaters, D.; Dirks, A.C.; Kappler, L.A.; Mitchell, J.K.; Quijada, L.; Vandegrift, R.; Buyck, B.; Pfister, D.H. A preliminary checklist of fungi at the Boston Harbor islands. Northeast. Nat. 2018, 25, 45-76. [CrossRef]

41. Capella-Gutiérrez, S.; Silla-Martínez, J.M.; Gabaldón, T. TrimAl: A tool for automated alignment trimming in large-scale phylogenetic analyses. Bioinformatics 2009, 25, 1972-1973. [CrossRef] [PubMed]

42. Kalyaanamoorthy, S.; Minh, B.Q.; Wong, T.K.F.; von Haeseler, A.; Jermiin, L.S. ModelFinder: Fast model selection for accurate phylogenetic estimates. Nat. Methods 2017, 14, 587-589. [CrossRef]

43. Kumar, S.; Stecher, G.; Tamura, K. MEGA7: Molecular Evolutionary Genetics Analysis version 7.0 for bigger datasets. Mol. Biol. Evol. 2016, 33, 1870-1874. [CrossRef] [PubMed]

44. Nguyen, L.-T.; Schmidt, H.A.; von Haeseler, A.; Minh, B.Q. IQ-TREE: A fast and effective stochastic algorithm for estimating maximum likelihood phylogenies. Mol. Biol. Evol. 2015, 32, 268-274. [CrossRef] [PubMed]

45. Chernomor, O.; von Haeseler, A.; Minh, B.Q. Terrace aware data structure for phylogenomic inference from supermatrices. Syst Biol. 2016, 65, 997-1008. [CrossRef]

46. Hoang, D.T.; Chernomor, O.; von Haeseler, A.; Minh, B.Q.; Vinh, L.S. UFBoot2: Improving the ultrafast bootstrap approximation. Mol. Biol. Evol. 2017, 35, 518-522. [CrossRef]

47. Wurzbacher, C.; Larsson, E.; Bengtsson-Palme, J.; Van den Wyngaert, S.; Svantesson, S.; Kristiansson, E.; Kagami, M.; Nilsson, R.H. Introducing ribosomal tandem repeat barcoding for fungi. Mol. Ecol. Resour. 2018, 19, 118-127. [CrossRef]

48. Stangl, J.; Veselský, J. Risspilze der Section Lilacinae Heim. Česká Mykol. 1982, 36, 85-99.

49. Kuyper, T.W. A revision of the genus Inocybe in Europe 1. Subgenus Inosperma and the smooth-spored species of subgenus Inocybe. Persoonia 1986, 3, 1-247.

50. Stangl, J. Die Gattung Inocybe in Bayern. Hoppea 1989, 46, 1-409.

51. Ludwig, E. Pilzkompendium. Band 4; Fungicon Verlag: Berlin, Germany, 2017.

52. Ferrari, E.; Bandini, D.; Boccardo, F. Inocybe (Fr.) Fr., Terzo Contributo; Fungi non delineati 73/74; Edizioni Candusso: Alassio, Italy, 2014.

53. Alessio, C.L. Complemento allo studio del Genere Inocybe: $8^{\circ}$ contributo. Riv. Micol. Assoc. Micol. Bresadola 1987, 30, 79-89.

54. Esteve-Raventós, F. Two new species of Inocybe (Cortinariales) from Spain, with a comparative type study of some related taxa. Mycol. Res. 2001, 105, 1137-1143. [CrossRef]

55. Smith, A.H.; Stuntz, D.E. New or noteworthy fungi from Mount Rainier National Park. Mycologia 1950, 42, 80-134. [CrossRef] 